\title{
Morphological and Genetic Subdivision of Sockeye Salmon Samples, Oncorhynchus nerka, Collected within the Period of Spawning Migration in Outfalls of Kamchatka Rivers
}

\author{
Anastasia M. Khrustaleva and Nataliya V. Klovach \\ Russian Federal Research Institute of Fisheries and Oceanography (VNIRO), 17 V. Krasnoselskaya Str., Moscow, \\ 107140, Russia
}

Keywords: sockeye salmon, Oncorhynchus nerka, mixed samples, morphological characteristics, genetic heterogeneity, SNP, clusterization and classification of samples

Sockeye salmon are characterized by extremely complex population structure: populations reproducing in different river watersheds (metapopulations) are subdivided into seasonal races, ecotypes, and subpopulations of isolated spawning grounds. Because of the genetic and morphological differentiation of the intraspecific forms, samples collected in the downstream reach of a river are normally heterogeneous. This includes both mixed samples from an estuary and samples collected during sockeye salmon spawning run in lower river flow. The objective of the paper was to analyze subdivision of sockeye salmon samples from the low course of East and West Kamchatka rivers, where (in tributaries and lakes) the most commercially important Asian stocks are reproduced.
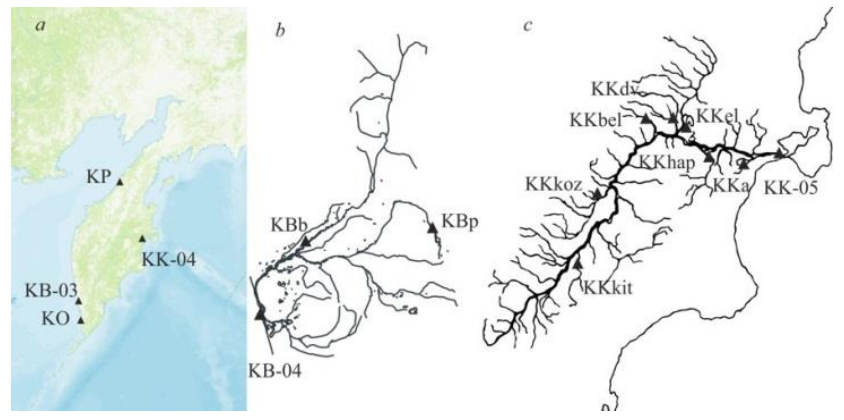

Fig. 1. Sampling location map: a-Kamchatka Peninsula, our data; b-Bol'shaya River drainage (Khrustaleva et al. 2014); c-Kamchatka River drainage (Khrustaleva et al. 2015; Habicht et al. 2010). Samples: KP-Palana River, KB03-Bol'shaya River, 2003, KO - Ozernaya River, KK-04Kamchatka River, 2004, KB-04-Bol'shaya River, 2004, KBp-Plotnikova River, KBb-Bystraya River, KK-05 Kamchatka River, 2005 (early race), KKa-Azabachye Lake (early race), KKhap — Khapitsa River, KKbel—Belaya River, KKdv—Dvuyurtochnaya River, KKel-Elovka River, KKkoz-Kozyrevka River, KKkit—Kitilgina River.

Table 1. Characteristics of sockeye salmon samples from East and West Kamchatka

\begin{tabular}{|c|c|c|c|c|c|}
\hline $\begin{array}{c}\text { Place of catch (mixed } \\
\text { sample ID) }\end{array}$ & Sample ID & $\begin{array}{c}n \text { of biologically (genetically) } \\
\text { analyzed samples }\end{array}$ & Dates of catch & $\begin{array}{c}\text { Sample } \\
\text { description }\end{array}$ & $\begin{array}{l}\text { Proportion of } \\
\text { females, } \%\end{array}$ \\
\hline \multirow{7}{*}{$\begin{array}{l}\text { Palana R., lower } \\
\text { course (KP) }\end{array}$} & & & 10 July 2003 & \multirow{7}{*}{ Mass run } & \\
\hline & 1 Early & $93(30)$ & 11 July 2003 & & 51 \\
\hline & & & 12 July 2003 & & \\
\hline & & & 17 July 2003 & & \\
\hline & _lindare & $02(44)$ & 18 July 2003 & & 01 \\
\hline & 3 Late & $46(20)$ & 20 July 2003 & & 54 \\
\hline & & & 21 July 2003 & & \\
\hline \multirow{3}{*}{$\begin{array}{l}\text { Bolshaya R., lower } \\
\text { course }(\mathrm{KB})\end{array}$} & 1_Early & $16(16)$ & 23 July 2003 & $\begin{array}{l}\text { summer sockeye } \\
\text { salmon run }\end{array}$ & 47 \\
\hline & 2_Middle & $53(50)$ & 29 July 2003 & Summer sockeye & 42 \\
\hline & 3_Late & $54(35)$ & 30 July 2003 & salmon, main run & 57 \\
\hline \multirow{3}{*}{$\begin{array}{l}\text { Ozernaya R., mouth } \\
\text { (KO) }\end{array}$} & 1_Early & $50(45)$ & 04 August 2003 & \multirow{3}{*}{ Main run } & 68 \\
\hline & 2_Middle & $49(21)$ & 05 August 2003 & & 53 \\
\hline & 3_Late & $50(24)$ & 07 August 2003 & & 80 \\
\hline \multirow{7}{*}{$\begin{array}{l}\text { Kamchatka R., lower } \\
\text { course (KK-04) }\end{array}$} & $\begin{array}{l}\text { First } \\
\text { runners }\end{array}$ & $0(20)$ & $\begin{array}{l}29 \text { June } 2004 \\
30 \text { June } 2004\end{array}$ & \multirow{7}{*}{$\begin{array}{l}\text { Summer sockeye } \\
\text { salmon, mass run }\end{array}$} & - \\
\hline & & & 01 July 2004 & & \multirow{3}{*}{51} \\
\hline & 1_Early & $49(20)$ & 02 July 2004 & & \\
\hline & & & 05 July 2004 & & \\
\hline & 2_Middle & $71(33)$ & 06 July 2004 & & \multirow[t]{2}{*}{55} \\
\hline & & & 07 July 2004 & & \\
\hline & 3 Late & $20(20)$ & 09 July 2004 & & 47 \\
\hline
\end{tabular}

All correspondence should be addressed to A. Khrustaleva. email: mailfed@mail.ru 
Samples for the analysis were collected during mass spawning run of sockeye salmon in the lower courses of West (in 2003) and East (in 2004) Kamchatka Rivers (Table 1, Fig. 1a), as well as juveniles (underyearlings) and spawners were caught in Bol'shaya River drainage in 2004 (Khrustaleva et al. 2014) (Fig. 1b), and early race spawners were collected in the outfall of Kamchatka River in 2005 and in Azabachye Lake in 2004 (Khrustaleva et al. 2015). Moreover, Dr. Chris Habicht (Habicht et al. 2010) open data on allele frequencies of the same loci in samples from tributaries of the middle and upper reaches of the Kamchatka River were analyzed (Fig. 1c). Polymorphism of 45 previously described SNP loci (Smith et al. 2005; Elfstrom et al. 2006; Habicht et al. 2010) were investigated. The SNP genotyping was performed using TaqMan PCR at the School of Aquatic and Fishery Sciences (University of Washington) (Seeb et al. 2009). Statistical analysis included both standard approaches and clustering of the samples in the STRUCTURE 2.3.4. (Pritchard et al. 2000).
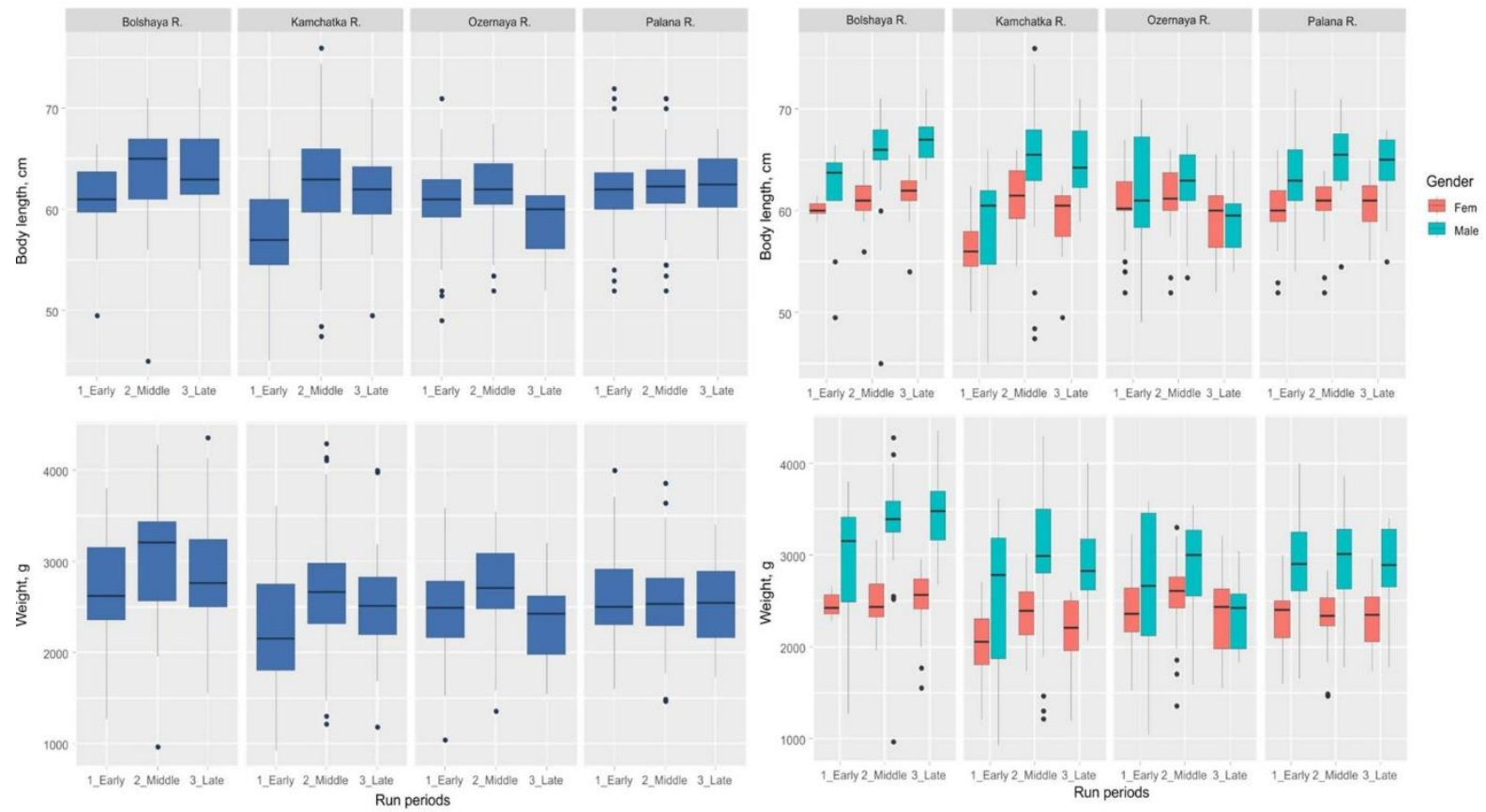

Fig 2. Boxplots of body length (SL) and weight (without internal organs) estimates of sockeye salmon from rivers of western and eastern Kamchtka by the periods of mass run.

Morphological and genetic heterogeneities of sockeye salmon samples collected in different periods of its spawning run as well as in mixed samples from the outfalls of West and East Kamchatka rivers were studied.

The size-mass characteristics of sockeye salmon in western Kamchatka rivers did not differ significantly (Mann-Whitney $U$-test) between the periods of the mass movement, with a number of exceptions (Fig. 2). Sockeye salmon from the 1_Early party of Bolshaya River were noticeably smaller, than caught during the mass run (29 and 30 July), but significant differences were revealed only for length estimates $(p=0.03)$. In Ozernaya River fishes from 1_Ealy and 2_Middle groups were larger, than those caught two days later (3_Late). Comparison of the first two samples revealed significant differences in gonad mass $(p=0.022)$, probably due to different ratios of males and females in the catch. The individuals from 1_Erly group were significantly larger than those caught on August 7 (3_Late), differences were found in all the biological characteristics studied $(p<0.001)$. A cause of the revealed differences is the different sex ratio in the samples, since the males of the Western Kamchatka sockeye are significantly larger than the females (Bugayev 1995): in the 2_Middle sample, the proportion of males was much higher than in 3_Late (Table 1). Fish from the first and third samples did not differ at any of the considered traits.

On the contrary for Kamchatka River the size-mass characteristics of adult fish caught on July 1-2 (1_Ealy), were significantly lower $(p<0.05)$ than in samples of later terms. The latter groups (2_Middle and 3_Late) did not differ among themselves either in length or in mass.

There wasn't any periodicity in estimates of allele frequencies of 45 SNP loci during mass spawning migration of sockeye salmon in the rivers of west coast of Kamchatka ( $p>0.05$, exact $G$ test).

The heterogeneity of allelic frequencies of 34 polymorphic SNP loci was revealed by the periods of the mass run of sockeye salmon in the mouth of the Kamchatka River (exact $G$ test): the samples of the first (First runners and 
1_Ealy) and the second (2_Middle and 3_Late) half of the mass run differed significantly $(p<0.01)$. However, these differences were mainly due to the variability of only two loci (One_RF-295 and One_MHC2_251v2). The identified genetic and morphological heterogeneity of the samples may be explained by a successive approach to the river mouth of spawning groups, reproduced in different parts of the river basin.

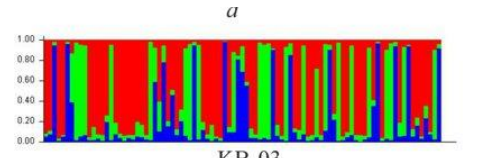

KB-03

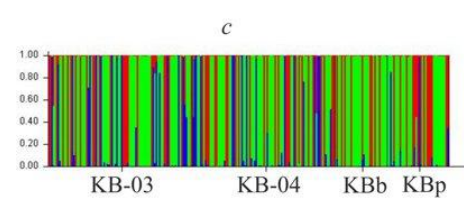

$e$

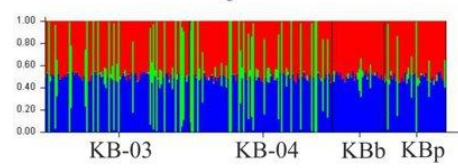

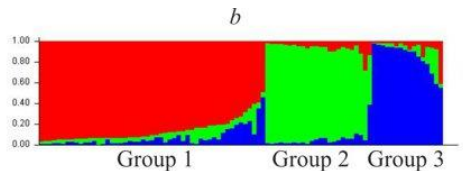

$d$
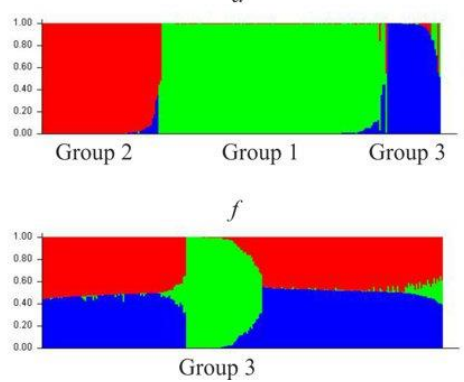

Fig. 3. Classification of mixed samples of sockeye salmon from Bol'shaya River drainage based on the algorithm of the STRUCTURE 2.3.4 $(\mathrm{K}=3)$ : a, $\mathrm{b}, \mathrm{e}$ - individuals sorted by dates and places of catch; $b, d, e$-individuals are ranked according to the probability of assigning them to the groups; $\mathrm{e}, \mathrm{f}-$ classification performed excluding mitochondrial loci.

Allele frequencies of polymorphic loci in pooled samples from estuaries of West Kamchatka were analyzed in STRUCTURE in order to identify relatively genetically homogeneous groups of individuals in mixed samples. For instance, Bolshaya River sample can be divided into three groups (Fig. 3a). These groups are also identified when all the samples from the Bolshaya River watershed are included (Fig. 3b). Analysis of the distribution of allelic frequencies of 36 polymorphic SNP loci in these groups showed that the first two groups differed only in the frequencies of the combined mitochondrial locus $O n e_{-} C y t B_{-} C O 1$ haplotypes, while the third group differed from the first two at most of the loci (Fig. 3c).

In the Bolshaya River basin late sockeye salmon (summer race) is represented by two ecological forms (ecotypes): the lake type (mainly populations of Nachikinskoe Lake, located in the upstream of the Plotnikova River) and the river type, reproduced in large tributaries: Bystraya River, Plotnikova River, Karymchina River, Bannaya River and others (Bugaev et al. 2002a; Zaporozhets et al. 2013). Analyzing the results obtained, it can be assumed that group 3 is mainly represented by lake fish, apparently from the Nachikinskoe Lake. In favor of this assumption the fact argued that in the basin of Bystraya River individuals belonging to this group were absent, and among the juveniles of the upper reach of Plotnikova River met sporadically. Moreover group 3 was relatively small and mainly represented by age class 2.3 .

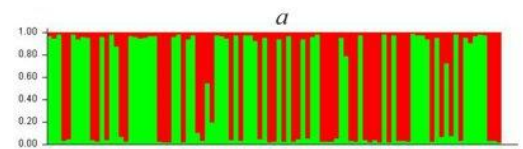

$c$

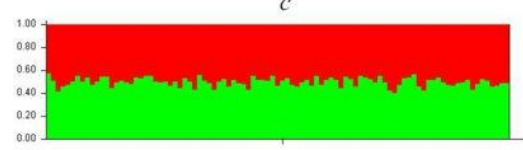

$\mathrm{KO}$

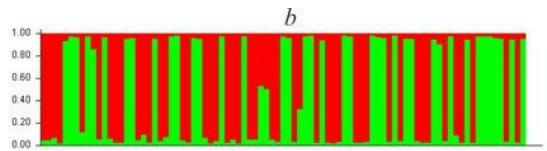

$d$

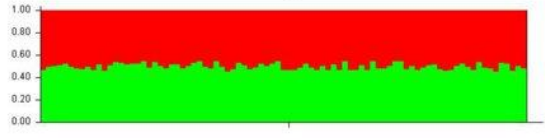

KP
Fig. 4. Classification of mixed samples of sockeye salmon from Ozernaya River $(\mathrm{a}, \mathrm{c})$ and Palana River (b, d) drainages based on the algorithm of the STRUCTURE 2.3.4 $(\mathrm{K}=2)$; c, $\mathrm{d}$-classification performed excluding mitochondrial loci.

In the mixed samples from Ozernaya River and Palana River there wasn't any phenotypic or genetic heterogeneity (Fig. 4). In both rivers reproduction of sockeye salmon is concentrated in a watershed of one large lake, therefore the habitat conditions of the populations are more uniform, and the isolation between them is predominantly sympatric. In addition, the sockeye salmon of both lakes are mainly represented by one seasonal race: in Palana River - 99\%, and in Ozernaya River-98\% of all sockeye falls on the late form (Bugaev and Dubynin 2002; Bugaev et al. 2002).

According to the results of the analysis in STRUCTURE in the mixed sample from the mouth of Kamchatka River in 2004, two groups of individuals were distinguished - group 1 and more numerous group 2 (Fig. 5). Moreover, in the beginning of the run group 2 was predominant, whereas in the second half of the run the individuals assigned to group 1 were encountered much frequently (Fig. 5a). The groups are significantly differentiated by most loci (20 of 34), with greatest contributions of One_MHC2_251v2 and One_GPH-414. 
Analysis of the phenotypic traits in both groups showed that group 2 was represented mainly by small and younger individuals, whereas in group 1 fish were, on average, older and larger. In addition, the proportion of individuals spent in fresh water for two years was significantly higher in group 1.
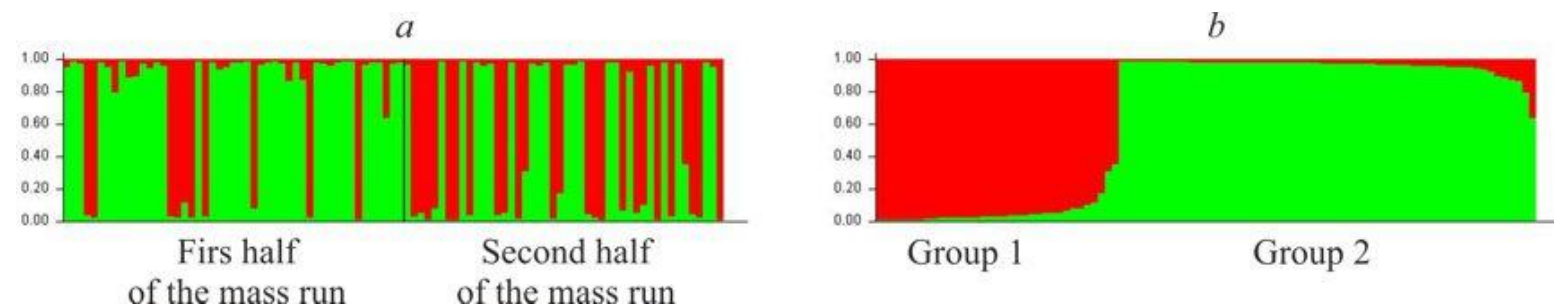

Fig. 5. Classification of a mixed sample of sockeye salmon from the Kamchatka River drainage, 2004, based on the algorithm of the STRUCTURE 2.3.4 $(\mathrm{K}=2)$ : a-individuals sorted by dates of catch; $\mathrm{b}$-individuals are ranked according to the probability of assigning them to the groups

We assumed that these groups belong to different subpopulations of summer sockeye salmon in Kamchatka River watershed (Bugaev 2011). Group 1 can be attributed to the grouping E, reproduced in the middle and lower reaches of the river, some of them enter the Azabachye Lake and stay there for several months. Group 2 can be classified as grouping B, which occupies upstream tributaries. Juveniles of the grouping spend winter on spawning grounds and migrate downstream at the age of 1+ (Bugaev 2011). Our findings are supported by the results of multidimensional scaling (MDS) using a matrix of Euclidean distances calculated by the allelic frequencies of SNP loci in sockeye samples from different parts of Kamchatka River (Fig. 6). According to the first coordinate, three groups of populations can be distinguished in the diagram: a grouping of tributaries of the middle course, which also included group 1 and a sample of early sockeye from the outfall in 2005; salmon from upper tributaries, represented by one sample from Kitilgina River and forming a shared cluster with group 2; and a set of samples from the tributaries of the lower reach and from the Kozyrevka River. We can hypothesize that the most numerous in the watershed sockeye salmon of Azabachye Lake can also be sporadically represented in both groups. Most likely, it migrates a bit later, and our samples did not cover it.

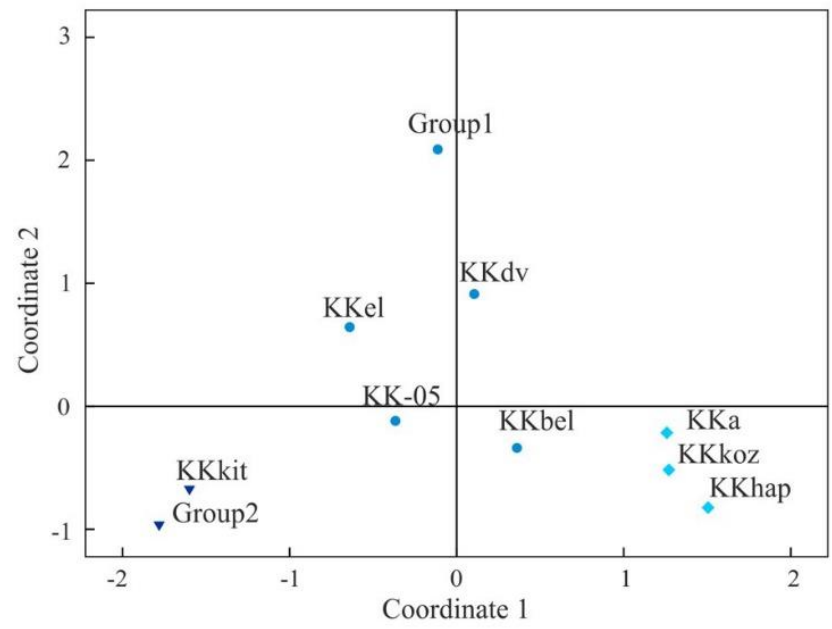

Fig. 6. Multidimensional scaling diagram (MDS), plotted on Euclidean distances, for samples of sockeye salmon from the Kamchatka River drainage.

Differences between the samples collected during mass spawning run in the main course of Kamchatka River indicate a successive character of migration of different spawning groups reproducing in distinct parts of the watershed: at the beginning of the run, individuals reproducing in the spawning grounds of the middle reach of the river predominate, then the upstream groups migrate and, probably, some days later Azabachye Lake fish comes.

Acknowledgments-We thank to Dr. J. Seeb (School of Aquatic \& Fishery Sciences, University of Washington, Seattle) for comprehensive assistance and laboratory work organization. 


\section{REFERENCES}

Bugaev, V.F. 2011. Asian Sockeye Salmon (freshwater period of life, biological structure, population dynamics. Publishing house "Kamchatpress", Petropavlovsk-Kamchatsky. 292 pp.

Bugaev, V.F. and V.A. Dubynin. 2002. Factors Affecting the Biological Indices and Population Dynamics of Sockeye Salmon Oncorhynchus nerka from the Ozernaya and Kamchatka Rivers. Izv. TINRO 130: 679-757. (In Russian with English abstract)

Bugaev, V.F., A.G. Ostroumov, K.Yu. Nepomnyashchii, and A.V. Maslov. 2002a. Some Specific Features of Biology of Sockeye Salmon Oncorhynchus nerka from the Bolshaya River (Western Kamchatka) and Factors Affecting Its Biological Indices. Izv. TINRO 130: 758-776. (In Russian with English abstract)

Bugaev, V.F., L.V. Milovskaya, E.V. Lepskaya et al. 2002b. The study of sockeye salmon Oncorhynchus nerka of Palansky Lake 1990-2001 (northwestern Kamchatka). Izv. TINRO 130: 777-791. (In Russian with English abstract)

Elfstrom, C.M., C.T. Smith, and J.E. Seeb. 2006. Thirty-two single nucleotide polymorphism markers for highthroughput genotyping of sockeye salmon. Mol. Ecol. Notes. 6(4): 1255-1259.

Habicht, C., L.W. Seeb, K.W. Myers et al. 2010. Summer-fall distribution of stocks of immature sockeye salmon in the Bering Sea as revealed by single-nucleotide polymorphisms. Trans. Amer. Fish. Soc. 139(4): 1171-1191.

Khrustaleva, A.M., N.V. Klovach, O.F. Gritsenko, and J.E. Seeb. 2014. Intra- and interpopulation variability of southwestern Kamchatka sockeye salmon Oncorhynchus nerka inferred from the data on single nucleotide polymorphism. Russian Journal of Genetics (Genetika). 50(7): 736-748.

Khrustaleva, A.M., N.V. Klovach, E.V. Vedischeva et al. 2015. Genetic differentiation of sockeye salmon Oncorhynchus nerka from Kamchatka River basin and the lake-river systems of the west coast of the Bering sea as inferred from data on single nucleotide polymorphism. Russian Journal of Genetics (Genetika). 51(10): 980-991.

Pritchard, J.K., M. Stephens, and P. Donnelly. 2000. Inference of population structure using multilocus genotype data. Ibid. 155(2): 945-959.

Seeb, J.E., C.E. Pascal, R. Ramakrishnan, and L.W. Seeb. 2009. SNP genotyping by the 5'-nuclease reaction: advances in high throughput genotyping with non-model organisms. In Methods in molecular biology, single nucleotide polymorphisms. Edited by A. Komar. Humana Press, New York. pp. 277-292.

Smith, C.T., C.M. Elfstrom, J.E. Seeb, and L.W. Seeb. 2005. Use of sequence data from rainbow trout and Atlantic salmon for SNP detection in Pacific salmon. Mol. Ecol. 14: 4193-4203.

Zaporozhets, O.M., G.V. Zaporozhets, and Zh.Kh. Zorbidi. 2013. Stock dynamics and biological parameters of pacific salmons in the Bolshaya River (West Kamchatka). Izv. TINRO 174: 38-67. (In Russian with English abstract) 